\title{
Review of Decision-Making in Game Tasks in Elderly Participants with Alzheimer Disease and Mild Cognitive Impairment
}

\author{
Alaise Silva Santos de Siqueira ${ }^{a}$ b Juliana Emy Yokomizo ${ }^{c}$ \\ Wilson Jacob-Filhob Mônica Sanches Yassudad, e Ivan Aprahamian ${ }^{a}$, b, f \\ ${ }^{a}$ Department and Institute of Psychiatry, ${ }^{b}$ Division of Geriatrics, Department of Internal \\ Medicine, ' Old Age Research Group (PROTER), Department and Institute of Psychiatry, \\ ${ }^{\mathrm{d}}$ Department of Neurology, Faculty of Medicine, University of São Paulo, e'School of Arts, \\ Sciences and Humanities of the University of São Paulo, São Paulo, and ${ }^{\mathrm{f}}$ Department of \\ Internal Medicine, Faculty of Medicine of Jundiaí, Jundiaí, Brazil
}

\section{Keywords}

Neuropsychological assessment $\cdot$ Alzheimer disease $\cdot$ Mild cognitive impairment

\begin{abstract}
Background: Changes in decision-making (DM) have recently been investigated in patients with Alzheimer disease (AD) or mild cognitive impairment (MCI). DM is highly relevant to everyday functioning and autonomy. It relies on several cognitive abilities, such as semantic and episodic memory, as well as aspects of executive functioning. We conducted a systematic review of DM in older adults with MCI and AD. Summary: Only 5 studies whose main objective was to evaluate the DM performance were selected. The results extracted indicated that DM in ambiguity and in at-risk situations are both impaired in probable AD patients. MCI patients have difficulty making advantageous decisions under ambiguity and at risk, similar to patients with probable AD but they are less impaired. Key Messages: DM deficits may be a predictor of cognitive impairment and conversion to dementia and its potential clinical value should be further explored in longitudinal studies involving direct comparison between $M C I$ and $A D$ patients.

(C) 2017 S. Karger AG, Basel
\end{abstract}

\section{Introduction}

There is a need to better understand less frequently investigated cognitive abilities among older adults that might aid in the clinical distinction between normal cognition and early decline [1]. Decision-making (DM) is highly relevant to everyday functioning and 
autonomy. It relies on several cognitive abilities, such as semantic and episodic memory, as well as aspects of executive functioning; therefore, it is plausible to suppose that it may be affected in various degrees of cognitive impairment. Unfortunately, few studies have investigated whether DM can contribute to dementia and mild cognitive impairment (MCI) diagnosis.

DM consists of the process of choosing between two or more competing alternatives that require a cost-benefit analysis of each option and the estimated consequences in the short, medium and long term [2]. It is influenced by several factors such as adaptive strategies, personal preferences, reward evaluation, and conditioning. Parameters such as uncertainty, ambiguity, risk analysis, and the calculation of the probability of success of a given choice are part of the DM process [3]. Psychologists have attempted to create research paradigms that mimic everyday DM challenges. To date, there are at least two classic types of DM tasks that have been described: the "under risk" results of an action that can be predicted through calculation of well-defined or estimated probabilities $[4,5]$ and the "ambiguity type," which occurs when information about the likelihood of success is not amenable to prediction and the expected advantage of different options is incalculable [6].

The concept of DM has been widely studied through fictional game situations in clinical practice [7]. The most frequently used instruments in DM assessment are the Iowa Gambling Task (IGT) $[8,9]$ (through an ambiguity type of DM), the Associated Gambling Probability (AGP) [10] (an under-risk type), and the Game of Dice Task (GDT) [11] in its original or modified forms (GDT-D) [12].

Further studies in this area are needed, as a better understanding of the complex biological and cognitive processes that affect DM can lead to better diagnostic tools to evaluate this cognitive ability as well as to the development of effective rehabilitation strategies for patients who are vulnerable to DM failures [3]. Taking into account that systematic reviews regarding DM and dementia or MCI are lacking, the present study aimed to perform a review on DM in MCI and Alzheimer disease (AD).

\section{Methods}

\section{Selection of Studies}

A computerized systematic search for DM studies in older adults with MCI or AD was done in MEDLINE, PsychINFO, and EMBASE databases from January 1980 until July 2016. We used the following MeSH terms and keywords: "Alzheimer's dementia," "Alzheimer's disease," "Alzheimer" OR “mild cognitive impairment," "MCI" AND "decision-making," "decision making" OR "game task," and "game tasking". The initial search yielded 3,767 references and from those, 125 abstracts were selected after excluding duplications and the inspection of the title. The inclusion criteria of the studies were: age of 60 years or older; sample consisting of elderly people with MCI or AD; studies available in English; clinical studies; original studies; case-control studies; studies whose main objective was to evaluate DM performance; and instruments to evaluate DM tasks. Exclusion criteria were: letters to the editor, editorials or reviews. After the analysis of these abstracts, 26 studies were selected to be read and analyzed. A manual search of additional studies was also performed in the reference list of the selected articles. Finally, 5 articles were selected to be included in the present review. The search and screening of studies was performed by 2 authors (A.S.S.S. and J.E.Y.). Additionally, 2 other authors tested the search strategy independently (M.S.Y. and I.A.). All studies that were screened, included, and assessed for eligibility in this review are presented using the PRISMA flow diagram (Fig. 1).

Due to the limited number of studies, we preferred to avoid the use of a cutoff score based on quality assessment for the exclusion of studies or any methodological quality of the studies. 
de Siqueira et al.: Review of Decision-Making in Game Tasks in Elderly Participants with Alzheimer Disease and Mild Cognitive Impairment

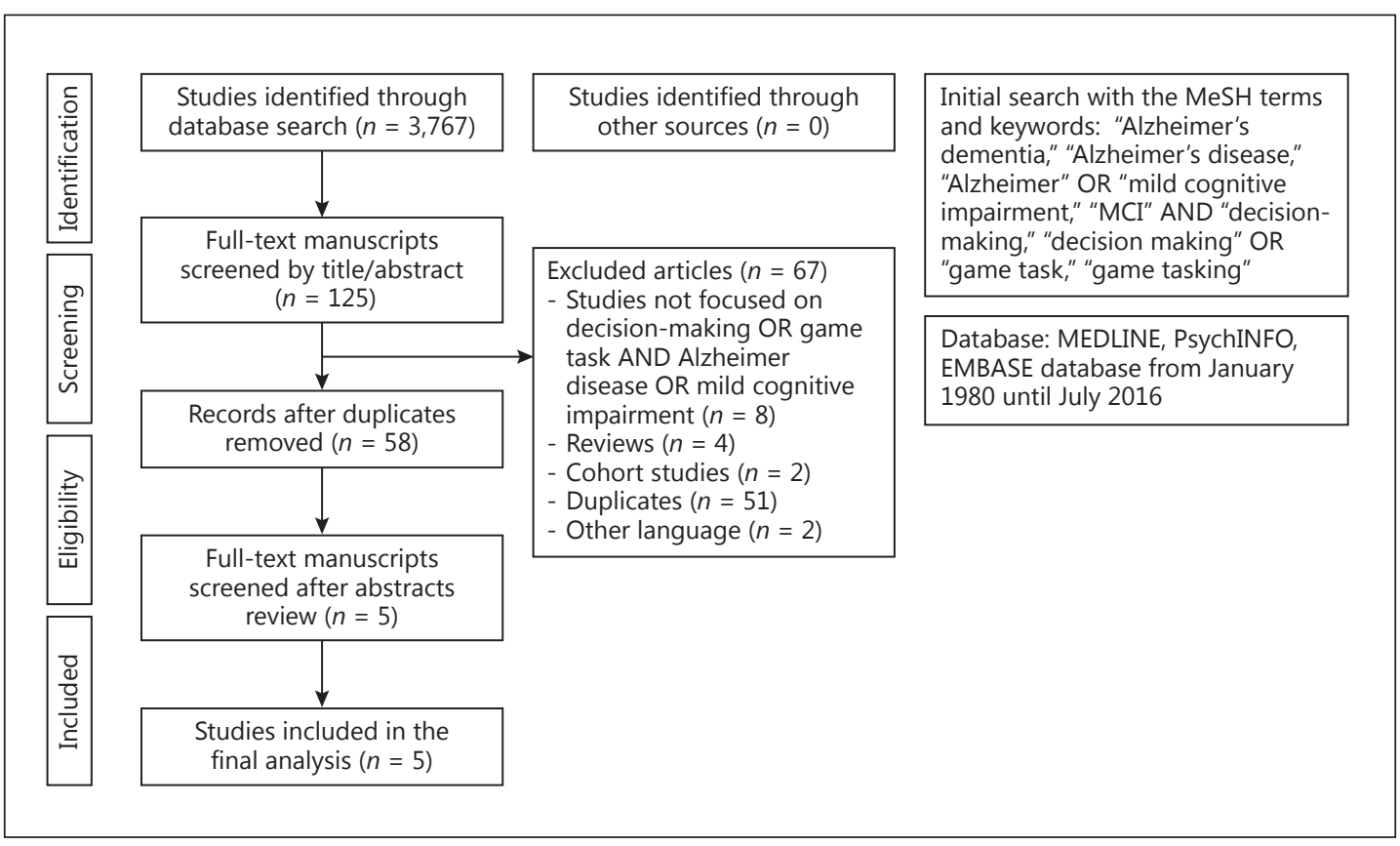

Fig. 1. Flow diagram of the systematic search.

\section{Results}

Five studies fulfilled our inclusion criteria for studies of DM involving older adults with MCI or AD [10,12-15] (Table 1). All studies were performed in memory clinics. Four studies were conducted in Austria at the same center [10,12-14]. One study was done in France [15]. The samples were composed of outpatients diagnosed with mild AD or MCI. In the studies, diagnosis of MCI was based on the criteria proposed by Petersen [16]: memory complaints without functional impairment and cognitive impairment lower than 1.5-2.0 standard deviations from normative scores in formal neuropsychological testing. One study [12] used the 2011 MCI criteria of the National Institute on Aging-Alzheimer's Association besides Petersen's criteria. AD subjects were diagnosed according to the NINCDS-ADRDA 1984 criteria.

\section{Subjects Compared to Controls}

In the first study, 22 older adults with $\mathrm{MCI}$ and 22 healthy individuals were assessed using the IGT [14]. The IGT is a computerized task, in which the participant must choose between 4 different card decks. Although it is not explicit to the participants, 2 of the 4 decks are advantageous, as they lead to lower gains but lower losses, and the other 2 are disadvantageous, as they lead to higher gains but also to extremely high losses. The rules on gains and losses are not explained to the participants; therefore, to solve the task successfully, participants must discover the rules using the feedback they receive after each choice. For more details regarding this task, please consult the original studies of Bechara et al. [8,9]. This study also used the AGP task. In this computerized task, participants are instructed to imagine they are participating in a lottery game in order to win as much money as possible. On each turn, the participant must decide whether to bet a safe amount yielding a small loss or gain, or to risk a high value yielding a possible high loss or gain. For a more detailed description of the task, please refer to Sinz et al. [10]. The exclusion criteria in the study were a history of stroke, traumatic brain injury, substance abuse, or the presence of neurological, psychi- 
de Siqueira et al.: Review of Decision-Making in Game Tasks in Elderly Participants with Alzheimer Disease and Mild Cognitive Impairment

Table 1. Decision-making studies in mild cognitive impairment and Alzheimer dementia

\begin{tabular}{|c|c|c|c|c|c|c|c|}
\hline $\begin{array}{l}\text { First author } \\
\text { [Ref.], } \\
\text { year, } \\
\text { country }\end{array}$ & Aim of the studies & $\begin{array}{l}\text { Diagnostic } \\
\text { criteria }\end{array}$ & Sample characteristics & Setting & $\begin{array}{l}\text { Instruments } \\
\text { for } \\
\text { evaluation } \\
\text { of DM }\end{array}$ & Results & Comments \\
\hline $\begin{array}{l}\text { Zamarian } \\
{[14],} \\
2011 \\
\text { Austria }\end{array}$ & $\begin{array}{l}\text { Investigate } \\
\text { whether patients } \\
\text { with MCI have } \\
\text { difficulties in DM } \\
\text { under ambiguity or } \\
\text { risk }\end{array}$ & $\begin{array}{l}\text { MCI was } \\
\text { diagnosed based } \\
\text { on Petersen } \\
\text { criteria }(2004)\end{array}$ & $\begin{array}{l}22 \mathrm{MCI} \text { participants ( } 8 \\
\text { women), mean age } 77.5 \\
\text { years and education } 9 \\
\text { years } \\
22 \text { healthy controls ( } 11 \\
\text { women), mean age } 76 \\
\text { years and education } 9.5 \\
\text { years }\end{array}$ & $\begin{array}{l}\text { Me- } \\
\text { mory } \\
\text { clinic }\end{array}$ & $\begin{array}{l}\text { Iowa } \\
\text { Gambling } \\
\text { Task and } \\
\text { Associated } \\
\text { Gambling } \\
\text { Probability } \\
\text { Task }\end{array}$ & $\begin{array}{l}\text { MCI participants } \\
\text { showed random } \\
\text { responses from } \\
\text { advantageous or } \\
\text { disadvantageous } \\
\text { options in DM tasks } \\
\text { under ambiguity or } \\
\text { risk }\end{array}$ & $\begin{array}{l}\text { Small sample } \\
\text { Evaluated both DM } \\
\text { under risk/ambiguity } \\
\text { Correlation of DM } \\
\text { with executive } \\
\text { functions } \\
\text { No neuroimaging data }\end{array}$ \\
\hline $\begin{array}{l}\text { Pertl [12], } \\
\text { 2015, } \\
\text { Austria }\end{array}$ & $\begin{array}{l}\text { Assess how MCI } \\
\text { patients make } \\
\text { decisions under } \\
\text { risk and the } \\
\text { relationship } \\
\text { between DM, ratio } \\
\text { processing, } \\
\text { numerical abilities, } \\
\text { and executive } \\
\text { functions }\end{array}$ & $\begin{array}{l}\text { MCI was } \\
\text { diagnosed based } \\
\text { on Petersen } \\
\text { criteria (2004) } \\
\text { and NIA-AA } \\
\text { statement } 2011\end{array}$ & $\begin{array}{l}22 \mathrm{MCI} \text { participants (11 } \\
\text { women), mean age } 75 \\
\text { years and education } 11 \\
\text { years } \\
29 \text { healthy controls (19 } \\
\text { women), mean age } 73 \\
\text { years and education } 10 \\
\text { years }\end{array}$ & $\begin{array}{l}\text { Me- } \\
\text { mory } \\
\text { clinic }\end{array}$ & $\begin{array}{l}\text { Modified } \\
\text { Game of } \\
\text { Dice Task }\end{array}$ & $\begin{array}{l}\text { MCI participants } \\
\text { showed difficulty in } \\
\text { advantageous } \\
\text { decision when the } \\
\text { situation was } \\
\text { complex on ratio } \\
\text { processing; needed } \\
\text { several tests to } \\
\text { improve their } \\
\text { performance }\end{array}$ & $\begin{array}{l}\text { Small sample } \\
\text { Correlated DM, } \\
\text { emotion processing } \\
\text { and executive function } \\
\text { Evaluated only DM } \\
\text { under risk } \\
\text { Evaluated DM from } \\
\text { basic DM tasks }\end{array}$ \\
\hline $\begin{array}{l}\text { Delazer } \\
{[13]} \\
2007 \\
\text { Austria }\end{array}$ & $\begin{array}{l}\text { Assess whether the } \\
\text { GDT could } \\
\text { separate mild AD } \\
\text { from healthy } \\
\text { controls }\end{array}$ & $\begin{array}{l}\text { AD was } \\
\text { diagnosed based } \\
\text { on the NINCDS- } \\
\text { ADRDA criteria } \\
(1984)\end{array}$ & $\begin{array}{l}19 \text { AD participants ( } 14 \\
\text { women), mean age } 74.3 \\
\text { years and education } 10.9 \\
\text { years } \\
25 \text { healthy controls ( } 13 \\
\text { women), mean age } 70.3 \\
\text { years and education } 11.3 \\
\text { years }\end{array}$ & $\begin{array}{l}\text { Me- } \\
\text { mory } \\
\text { clinic }\end{array}$ & $\begin{array}{l}\text { Game of } \\
\text { Dice Task }\end{array}$ & $\begin{array}{l}\text { AD participants } \\
\text { switched more often } \\
\text { between safe and } \\
\text { risky alternatives } \\
\text { and showed } \\
\text { patterns of less } \\
\text { consistent decisions }\end{array}$ & $\begin{array}{l}\text { Small sample } \\
\text { Evaluated only DM } \\
\text { under risk } \\
\text { Correlated DM with } \\
\text { executive functions } \\
\text { No neuroimaging data }\end{array}$ \\
\hline $\begin{array}{l}\text { Sinz [10], } \\
2008, \\
\text { Austria }\end{array}$ & $\begin{array}{l}\text { Investigate DM } \\
\text { under ambiguity } \\
\text { with implicit rules } \\
\text { and under risk } \\
\text { with explicit rules } \\
\text { in AD }\end{array}$ & $\begin{array}{l}\text { AD was } \\
\text { diagnosed based } \\
\text { on the NINCDS- } \\
\text { ADRDA criteria } \\
(1984)\end{array}$ & $\begin{array}{l}22 \text { AD participants (18 } \\
\text { women), mean age } 76.6 \\
\text { years and education } 9.5 \\
\text { years } \\
22 \text { healthy controls }(17 \\
\text { women), mean age } 75.2 \\
\text { years and education } 10 \\
\text { years }\end{array}$ & $\begin{array}{l}\text { Me- } \\
\text { mory } \\
\text { clinic }\end{array}$ & $\begin{array}{l}\text { Iowa } \\
\text { Gambling } \\
\text { Task and } \\
\text { Associated } \\
\text { Gambling } \\
\text { Probability } \\
\text { Task }\end{array}$ & $\begin{array}{l}\text { AD participants } \\
\text { showed impairment } \\
\text { at both DM under } \\
\text { ambiguity and risk, } \\
\text { shifted more } \\
\text { frequently among } \\
\text { decks and chose } \\
\text { random strategies }\end{array}$ & $\begin{array}{l}\text { Small sample } \\
\text { Evaluated both DM } \\
\text { under risk/ambiguity } \\
\text { Correlation of DM } \\
\text { with executive } \\
\text { functions } \\
\text { No neuroimaging data }\end{array}$ \\
\hline $\begin{array}{l}\text { Bayard } \\
\text { [15], } \\
\text { 2014, } \\
\text { France }\end{array}$ & $\begin{array}{l}\text { Investigate the } \\
\text { relationship } \\
\text { between conscious } \\
\text { knowledge of } \\
\text { contingencies and } \\
\text { DM performances } \\
\text { under conditions } \\
\text { of uncertainty in } \\
\text { AD and MCI }\end{array}$ & $\begin{array}{l}\text { MCI was } \\
\text { diagnosed based } \\
\text { on Petersen } \\
\text { criteria (1999) } \\
\text { AD was } \\
\text { diagnosed based } \\
\text { on the NINCDS- } \\
\text { ADRDA criteria } \\
\text { (1984) }\end{array}$ & $\begin{array}{l}20 \text { MCI participants, } \\
\text { mean } 79.5 \text { years and } \\
\text { education } 7.5 \text { years } \\
20 \text { AD participants, mean } \\
\text { age } 82 \text { years and } \\
\text { education } 7 \text { years } \\
20 \text { healthy controls, } \\
\text { mean age } 71 \text { years and } \\
\text { education } 11.5 \text { years }\end{array}$ & $\begin{array}{l}\text { Me- } \\
\text { mory } \\
\text { clinic }\end{array}$ & $\begin{array}{l}\text { Iowa } \\
\text { Gambling } \\
\text { Task }\end{array}$ & $\begin{array}{l}\text { Decreased } \\
\text { performance in DM } \\
\text { was observed in } \\
\text { MCI and AD. Both } \\
\text { had opted more } \\
\text { often for decks with } \\
\text { high immediate } \\
\text { reward compared to } \\
\text { controls }\end{array}$ & $\begin{array}{l}\text { Small sample size } \\
\text { Significant group } \\
\text { differences in } \\
\text { education, intellect } \\
\text { and age } \\
\text { Only study comparing } \\
\text { MCI and AD } \\
\text { Evaluation of } \\
\text { relationship between } \\
\text { conscious knowledge } \\
\text { of contingencies and } \\
\text { DM tasks }\end{array}$ \\
\hline
\end{tabular}

DM, decision-making; MCI, mild cognitive impairment; AD, Alzheimer disease; NIA-AA, National Institute on Aging-Alzheimer's Association.

atric or metabolic diseases [14]. Each group was comparable in age and education $(p>0.05)$. In the IGT, healthy controls made advantageous selections more frequently $(z=-2.98, p=$ $0.003)$. In contrast, patients with MCI made random decisions and showed strategies that were simpler or weaker compared to healthy controls $(z=-2.69, p=0.007)$. In addition, they equally evaluated advantageous and disadvantageous decks. These results suggest that patients with MCI have difficulty learning from feedback and maintaining a favorable decision strategy over time. In the AGP task, MCI patients also differed significantly from healthy controls. MCI patients decided less advantageously than healthy controls $(z=-3.55, p<$ 0.001 ) and their standard response indicated that they based their decisions on the probability of winning and ignored the possibility of losing any sum of money. These results suggest that patients with MCI have difficulty integrating information from different sources 
de Siqueira et al.: Review of Decision-Making in Game Tasks in Elderly Participants with Alzheimer Disease and Mild Cognitive Impairment

and adapting their choices to changing situations [11]. Thus, the authors concluded that patients with MCI are impaired in DM in ambiguous or risky scenarios similar to patients with probable AD. The authors inferred that these difficulties can have a strong impact on daily functioning [14].

The second study [12] with MCI patients used the GDT-D. GDT-D assessed DM under risk, another task for reason processing, and a neuropsychological assessment of executive functions, mental calculation, language and comprehension [12]. The GDT-D is a modified version of the original GDT, which allows not only separating between risky and safe decisions, but it also distinguishes between ideal safe decisions in risky behaviors. The GDT-D gives the participant the opportunity to double their earning potential or loss and the most advantageous alternative is not the most conservative one, as is the case in the original GDT. In the GDT-D, participants decide more advantageously when they choose to double their earnings or losses after selecting among alternatives of 4-digit combinations [17]. The aim of this study was to characterize the performance of MCI patients in DM under risk. There were no significant differences $(p>0.1)$ in relation to age, education, or gender between MCI and healthy participants [12]. Similarly to the first study, neuropsychological tests indicated worse performance of $\mathrm{MCI}$ patients compared to the control group. The groups did not differ from each other in terms of anxiety or depression symptoms. In the reasoning task, MCI patients presented lower scores $(\mathrm{U}=171.00, p=0.005)$. In regard to DM under risk, significant differences were found between the groups in the GDT-D, but not in basic DM tasks (U $=205.00$, $p=0.030)$. In the GDT-D, patients often took higher risks than the controls $(\mathrm{U}=192.50, p=$ 0.015). A detailed inspection of performance suggested slower learning among MCI patients $(\mathrm{U}=196.00, p=0.019)$. The results of this study indicated that MCI patients have difficulty in DM when the situation is complex.

\section{AD Subjects Compared to Controls}

The first study of DM evaluation of probable mild AD patients compared to healthy controls used the computerized GDT [13]. For a more detailed description of the task, please see Brand et al. [11]. The answers to tasks were given verbally by the participant and were selected by the examiner by a mouse click. In this study, 19 AD patients with a mean MiniMental State Examination score of $25.2 \pm 2.8$ were compared to 25 healthy elderlies, with no significant differences with regard to demographic variables and levels of anxiety and depression. AD participants shifted their responses more frequently between safe and risky alternatives $\left(t_{42}=-2.57, p=0.02\right)$ and showed response patterns that were less consistent than healthy older adults $\left(t_{42}=-2.43, p=0.02\right)$. With respect to performance changes during the task, healthy participants had a stronger tendency for safe and advantageous responses. While the healthy controls showed a long learning pattern, patients with AD did not adapt to the task challenges $\left(t_{39}=2.18, p=0.04\right)$.

The second study evaluated 22 mild AD patients (mean Mini-Mental State Examination score of $23.4 \pm 2.4$ ) compared to healthy controls with both the computerized IGT and AGP instruments [10]. Demographic variables (age, education) and scores of anxiety and depression were also not significantly different between the groups. In this study, the IGT analyses revealed a significant difference between the groups $\left(F_{1,38}=15.03, \mathrm{MSE}=2.40, p<0.0001\right)$. The frequency of advantageous choices increased significantly over the task in the control group, while this pattern was not found in AD (control group block 1 vs. 5: $t_{21}=-4.73, p<$ $0.001)$. In addition, AD participants switched more often between advantageous and disadvantageous decks than controls $\left(F_{1,37}=24.29\right.$, MSE $\left.=15.80, p<0.0001\right)$. In the AGP task, AD participants showed less advantageous choices than healthy controls. They bet more often in the choices with low odds of winning, and less often in those with higher probability of success (condition $p=0.125: t_{40}=-3.93, p<0.01$; condition $p=0.375: t_{40}=-3.10, p<0.01$ ). 
de Siqueira et al.: Review of Decision-Making in Game Tasks in Elderly Participants with Alzheimer Disease and Mild Cognitive Impairment

\section{Compared to AD}

The fifth and final study evaluated DM under ambiguity in older adults with MCI or AD and the explicit understanding of the contingencies in the IGT by participants [15]. The study involved 20 healthy controls, 20 patients with AD, and 20 participants with MCI. Patients were recruited from the Memory Clinic Centre Hospitalier du val d'Ariège in France. All participants were significantly different in age $(p<0.002)$, premorbid intellectual level $(p<$ $0.002)$, and education $(p<0.001)$, yet these variables were not associated with DM in the IGT (respectively, $z=-0.67, p=0.49 ; z=-1.76, p=0.08 ; z=-1.67, p=0.09$ ). Participants completed the computerized IGT and were then asked which decks generated higher gains or losses and the answers were classified as "Full explicit knowledge" or "No explicit knowledge." Reduced performance in the IGT was observed in both patient groups, as they more often chose decks with high immediate rewards compared to controls. Explicit understanding of contingencies was less frequent in MCI (10\%) and AD (10\%) patients than in controls $(55 \%)(p<0.006)$, with no difference between AD and MCI. Full explicit knowledge was associated with improved $\mathrm{DM}$ in both $\mathrm{MCI}$ and $\mathrm{AD}$ but not in healthy controls. MCI and AD patients may have impaired DM due to insufficient knowledge about task contingencies. This was the only study that assessed DM under ambiguity in both MCI and AD patients.

\section{Discussion}

The present study reviewed the current evidence regarding DM based on game tasks in $\mathrm{MCI}$ and AD patients. This review found a very small number of studies of DM in elderlies with $\mathrm{MCI}$ or AD. All 5 studies presented here had small samples of participants with MCI or AD, and 4 of them were from the same memory clinic center.

Two studies involving seniors with MCI revealed impairment in DM tasks under ambiguity or risk, as well as difficulty in clearly making advantageous decisions when the situation was either more complex or relied on different sources of information. Participants with MCI demanded several repetitions to improve performance $[12,14]$. Seniors diagnosed with AD seemed to have a higher impairment in DM tasks. Study results with AD samples suggested that decisions were taken at random, without the establishment of strategies or consistent response patterns developed over time $[10,13]$. These results indicated that mild AD participants cannot properly manage either ambiguity or risk scenarios. Bayard et al. [15], the only study to compare participants with $\mathrm{MCI}$ and $\mathrm{AD}$ in DM game tasks (IGT), suggested that elderly with MCI have equivalent DM deficits as compared to elderly with $\mathrm{AD}$ and both groups fail to gain explicit knowledge of IGT reward and punishment rules.

Deficits in executive function may occur early in the course of $\mathrm{AD}$ and are often evident at the MCI stage [18]. With AD progression, deficits in executive functions become more evident with changes in abstract reasoning, difficulty concentrating and performing calculations. As the clinical condition deteriorates, poor judgment and difficulty in planning and completing a task become apparent [19]. However, more recent results [15] suggested that declarative memory may also play an important role in DM. Amnestic patients may fail to associate their choices for decks with immediate gains or losses. In fact, studies involving amnestic patients with hippocampal damage reported they did not develop an advantageous profile in the IGT $[20,21]$.

Results from studies included in this review suggest that the assessment of DM in individuals with different levels of cognitive impairment can be useful in the early detection of individuals with higher risk of developing AD. Such findings are preliminary and there are several issues to be explored further. Studies with larger samples should perform comparisons between healthy controls and patients with MCI or AD, with participants paired in age, 
education and premorbid intelligence, in order to identify clear patterns of DM impairment, and overcome limitations in previous studies [15]. The evaluation of DM in longitudinal studies could also clarify whether observed deficits are common in healthy aging, if this ability declines prematurely or if DM decline accelerates at any point during the aging process. In addition, the joint evaluation of the two types of DM (in risk scenario and ambiguity) can provide important data regarding the involvement of different brain areas in impaired DM and if there are different patterns of brain activations during DM that could allow a distinction between diagnostic groups. Studies using both types of DM tasks should clarify whether a decline may be greater in one setting than in the other (risk and ambiguity) to better characterize in which contexts elderly with MCI or AD have greater difficulties. These findings may have implications for patient care or supervision and for rehabilitation strategies. It is also important to assess the impact of education in these tasks because older adults with lower education should present a similar profile to the one observed among the elderly with MCI. In fact, a recent study which investigates performance of healthy illiterate elderly on the IGT supported this claim [22].

\section{Conclusions}

The data available in the literature to date suggest that older adults with cognitive impairment, whether MCI or AD, present specific profiles of DM impairment. AD patients tend to move more frequently between safe and risky alternative patterns and show more random and less consistent responses compared to healthy elderly. DM in both ambiguity and risk scenarios is impaired in probable $\mathrm{AD}$ and MCI patients. These results suggest that patients with probable $\mathrm{AD}$ or $\mathrm{MCI}$ are at a higher risk of making improper decisions in daily life. These changes can have a major impact on daily functioning and safety and should be further investigated. From the standpoint of diagnosis, future findings may clarify whether the assessment of DM can predict pathological cognitive decline.

\section{Disclosure Statement}

The authors declare that they have no competing interests.

\section{References}

1 Salmon DP, Bondi MW: Neuropsychological assessment of dementia. Annu Rev Psychol 2009;60:257-282.

-2 Mata FG da, Neves FS, Lage GM, Moraes PHP, Mattos P, Fuentes D, Corrêa H, Malloy-Diniz L: Neuropsychological assessment of the decision making process in children and adolescents: an integrative review of the literature. Rev Psiquiatr Clin 2011;38:106-115.

-3 Gleichgerrcht E, Ibáñez A, Roca M, Torralva T, Manes F: Decision-making cognition in neurodegenerative diseases. Nat Rev Neurol 2010;6:611-623.

4 Brand M, Labudda K, Markowitsch HJ: Neuropsychological correlates of decision making in ambiguous and risky situations. Neural Netw 2006;19:1266-1276.

5 Brand M, Recknor CE, Grabenhorst F, Bechara A: Decisions regarding the ambiguity and decisions under risk: correlations with executive functions and comparisons of two different gambling tasks with implicit and explicit rules. J Clin Exp Neuropsychol 2007;29:86-99.

6 Bechara A: The role of emotion in making decisions: evidence from patients with neurological damage orbitofrontal. Brain Cogn 2004;55:30-40.

7 Jacus JP, Bayard S, Raffard S, Bonnoron S, Gély-Nargeot MC: Decision making in normal and pathological aging. Geriatr Psychol Neuropsychiatr 2012;1:437-444.

$>8$ Bechara A, Damasio H, Tranel D, Damasio AR: Deciding advantageously before knowing the advantageous strategy. Science 1997;275:1293-1295. 
-9 Bechara A, Damasio H, Tranel D, Anderson SW: Dissociation of working memory from decision making within the human prefrontal cortex. J Neurosci 1998;18:428-437.

10 Sinz H, Zamarian L, Benke T, Wenning GK, Delazer M: Impact of ambiguity and risk on decision making in mild Alzheimer's disease. Neuropsychologia 2008;46:2043-2055.

11 Brand M, Heinze K, Labudda K, Markowitsch HJ: The role of strategies in deciding advantageously in ambiguous and risky situations. Cogn Process J 2008;9:159-173.

12 Pertl MT, Benkea T, Zamarian L, Delazer M: Decision making and ratio processing in patients with mild cognitive impairment. J Alzheimers Dis 2015;48:765-779.

-13 Delazer M, Sinz H, Zamarian L, Benke T: Decision-making with explicit and stable rules in mild Alzheimer's disease. Neuropsychologia 2007;45:1632-1641.

14 Zamarian L, Weiss EM, Delazer M: The impact of mild cognitive impairment on decision making in two gambling tasks. J Gerontol Psychol Sci 2011;66:23-31.

15 Bayard S, Jacus JP, Raffard S, Gely-Nargeot MC: Conscious knowledge and decision making under ambiguity in mild cognitive impairment and Alzheimer disease. Alzheimer Dis Assoc Disord 2014;29:357-359.

16 Petersen RC: Mild cognitive impairment as a diagnostic entity. J Intern Med 2004;256:183-194.

17 Brand M, Schiebener J, Pertl MT, Delazer M: Know the risk, take the win: how executive functions and probability processing influence advantageous decision making under risk conditions. J Clin Exp Neuropsychol 2014;36:914-929.

-18 Weintraub S, Wicklund AH, Salmon DP: The neuropsychological profile of Alzheimer's disease. Cold Spring Harb Perspect Med 2012;2:a006171.

19 Karantzoulis S, Galvin JE: Distinguish Alzheimer's disease from other forms of dementia key. Expert Rev Neurother 2011;11:1579-1591.

20 Gutbrod K: Decision-making in amnesia: do advantageous decisions require conscious knowledge of previous behavioural choices? Neuropsychologia 2006;44:1315-1324.

21 Gupta R, Duff MC, Denburg NL, Cohen NJ, Bechara A, Tranel D: Declarative memory is critical for sustained advantageous complex decision-making. Neuropsychologia 2009;47:1686-1693.

-22 Cassimiro L, Fuentes D, Nitrini R, Yassuda MS: Decision-making in cognitively unimpaired illiterate and loweducated older women: results on the Iowa gambling task. Arch Clin Neuropsychol 2016, Epub ahead of print. 